\title{
Bulk Metallic Glass-Forming Region of Four Multicomponent Alloy Systems
}

\author{
Ailong Zhang, Ding Chen* and Zhenhua Chen \\ School of Materials Science and Engineering, Hunan University, Changsha, 410082, P.R. China
}

We have evaluated the predictive ability of a simple method combing the efficient cluster packing model of metallic glasses proposed by Miracle, chemical mixing enthalpy and the normalized configurational entropy $S_{\text {config }} / R$ in rapidly locating the bulk metallic glass (BMG)forming composition region, in four multicomponent alloy systems. It is shown that the BMG-forming regions are similar in the topologically and chemically equivalent $\mathrm{La}-\mathrm{Al}-\mathrm{Co}$ and $\mathrm{Ce}-\mathrm{Al}-\mathrm{Co}$ alloy systems. However, in the topologically equivalent $\mathrm{Zr}-\mathrm{Ti}-\mathrm{Cu}-\mathrm{Ni}$ and $\mathrm{Zr}-\mathrm{Ti}-\mathrm{Al}-\mathrm{Cu}-\mathrm{Ni}$ alloy systems, the BMG-forming regions are quite different due to the difference in chemical bonding between constituents. BMG formation is most probably a compromise between topological and chemical effects. This method could be a new approach to rapidly locate BMG-forming composition region in multicomponent alloy systems, in which eutectic compositions are difficult to be measured in experiments. [doi:10.2320/matertrans.ME200801]

(Received October 7, 2008; Accepted February 20, 2009; Published April 8, 2009)

Keywords: bulk metallic glasses, glass-forming ability, multicomponent alloy systems

\section{Introduction}

It has been found that the glass-forming ability (GFA) is sensitive to composition in multicomponent alloy systems, ${ }^{1,2}$ and a number of criteria were proposed during the past decades to analyze and predict GFA. The qualitative criteria widely used are atomic size ratio, ${ }^{3,4)}$ multicomponent systems, ${ }^{5}$ ) heat of alloy formation ${ }^{3)}$ and valence electron concentration, ${ }^{6}$ ) and it is experimentally observed that glass formation occurs most easily in system possessing a deep eutectic minimum in the phase diagram and is usually restricted to a quite narrow concentration region around the eutectic. The commonly used quantitative parameters are $T_{\mathrm{rg}}$ $\left(T_{\mathrm{g}} / T_{1}\right),{ }^{7)} \Delta T_{\mathrm{x}}\left(T_{\mathrm{x}}-T_{\mathrm{g}}\right),{ }^{8)} \gamma\left(T_{\mathrm{x}}\left(T_{\mathrm{g}}+T_{1}\right)\right),{ }^{9)}$ etc. Unfortunately, none of them works well for all alloy systems, or even in a narrow composition region in a given alloy system. Furthermore, as pointed out by Rao et al., ${ }^{10)}$ these quantitative parameters have not true predictive ability because they need the alloy considered to be first prepared in glassy form, to be able to measure the glass transition temperature and/or the crystallization temperature. Therefore, many parameters have been proposed such as Gibbs free energy difference $\Delta G^{\mathrm{a}-\mathrm{ss}}$ between amorphous phase and solid solutions phase, ${ }^{10)}$ melting enthalpy $\Delta H_{\mathrm{m}},{ }^{11)}$ a product of thermodynamic parameter $\left(\Delta H^{\text {chem }} \times S_{\sigma} / k_{\mathrm{B}}\right){ }^{12)}$ to predict GFA of alloy systems without the need of preparing them in glass form. Recently, some efforts have been made to search for GFA of alloy systems by the CALPHAD (Calculation of Phase Diagram) approach. ${ }^{13-15)}$ It seems that a parameter, which can be used to accurately evaluate and predict GFA in a given alloy system to a narrow composition region, is not available up to now. However, we can locate the composition region with high GFA with one or more appropriate parameter, to some extent, to avoid tedious experimentally pinpointing of the whole composition region.

There are more and more difficulties in searching for the glass-forming regions of multicomponent alloy systems, with the increasing atomic species. Therefore, it will be helpful for theoretical and experimental researches to predict the glass-

*Corresponding author, E-mail: ma97chen@hotmail.com forming region of multicomponent alloy systems. For the past several years, glasses formation in La-Al-Co, Ce-Al-Co ternary alloy systems, $\mathrm{Zr}$-Ti-Cu-Ni quaternary alloy system and $\mathrm{Zr}-\mathrm{Ti}-\mathrm{Al}-\mathrm{Cu}-\mathrm{Ni}$ quinary alloy system are well studied, and they are suitable for investigating the topological and chemical effects on BMG formation.

In the present study, we evaluate the predictive ability of a method combing with the efficient cluster packing model of metallic glasses proposed by Miracle, ${ }^{16-18)}$ and chemical mixing enthalpy, the normalized configurational entropy, in rapidly locating composition region with high GFA, in which BMGs can be prepared, in these alloy systems.

\section{Method}

Recently, Miracle proposed an efficient cluster packing model for metallic glass. ${ }^{16-18)}$ In this model, solvent atoms $\Omega$ and solute atoms $\alpha$ form the solute-centered cluster in the first coordination shell, solute atoms $\beta$ and $\gamma$ occupy clusteroctahedral interstices and cluster-tetrahedral interstices, respectively. The convention chosen here is that the largest solutes are $\alpha$ atoms, and $\beta$ and $\gamma$ solutes are progressively smaller. Then, the solute-centered clusters are efficiently packed by faced-centered cubic (fcc) packing or simple cubic (sc) packing. The glass-forming composition in an alloy system can be calculated with the solute to solvent atomic radius ratio $\mathrm{R}$ in the first coordination shell and the packing style of the solute-centered clusters.

\section{Results and Discussion}

It was observed that the configurational entropy normalized by the gas constant $S_{\text {config }} / R=\Delta S^{\text {ideal }} / R=$ $-\sum_{i=\mathrm{A}, \mathrm{B} . \mathrm{C}} x_{i} \ln x_{i}$ for ternary metallic BMGs ranges from 0.8 to $1 .{ }^{12)}$ The contours of $S_{\text {config }} / R$ being equals to 0.8 and 1 are plotted in all figures.

The La-Al-Co ternary alloy system is topologically equivalent to the Ce-Al-Co ternary alloy system, because the atomic radius of $\mathrm{La}$ is equivalent to $\mathrm{Ce} \quad\left(\mathrm{r}_{\mathrm{La}}=\right.$ $\left.0.187 \mathrm{~nm} \approx \mathrm{r}_{\mathrm{Ce}}=0.182 \mathrm{~nm}^{18)}\right)$. The atomic radius of other atoms are $\mathrm{r}_{\mathrm{Al}}=0.143 \mathrm{~nm}, \mathrm{r}_{\mathrm{Co}}=0.128 \mathrm{~nm}$. The relative 


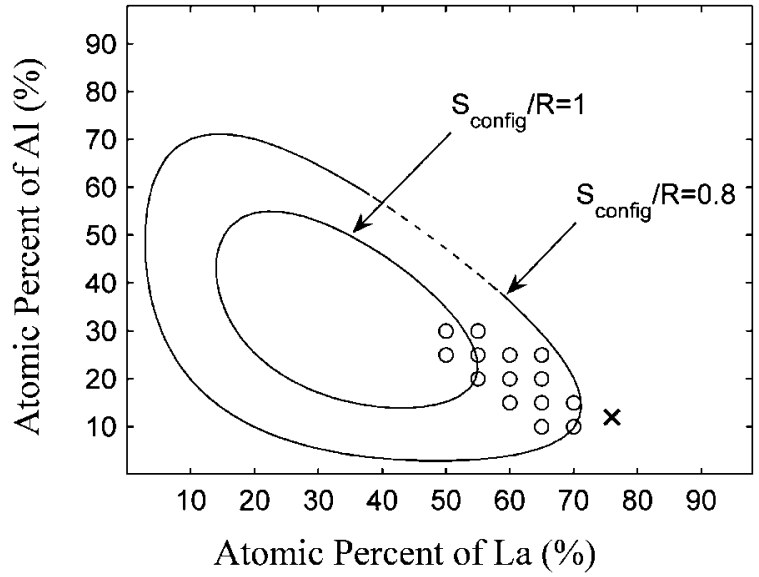

Fig. 1 The contours of $S_{\text {config }} / R$ being equals to 0.8 and 1 , in the composition diagram of the La-Al-Co alloy system. $\mathrm{BMGs}^{20)}$ are denoted by circles, the predicted glass-forming composition is denoted by tilted cross.

atomic radius of $\mathrm{Al}$ to $\mathrm{Ce}$ is $\mathrm{R}=0.786$, which is close to the critical radius ratio 0.799 with the coordination number $\mathrm{N}=10$, the relative atomic radius of $\mathrm{Co}$ to $\mathrm{Ce}$ is $\mathrm{R}=0.703$, which is close to the critical radius ratio 0.710 with the coordination number $\mathrm{N}=9$. According to Miracle's efficient cluster packing model, the structure of metallic glasses in both ternary systems is $\langle 10,9\rangle_{\mathrm{sc}}$, that is, sc packing of clusters with $\mathrm{La}(\mathrm{Ce})$ occupying $\Omega$ sites, Al occupying $\alpha$ sites, Co occupying $\beta$ sites, and there are no $\gamma$ sites. The chemical mixing enthalpies between constituents in both systems are $\Delta H_{\mathrm{La}-\mathrm{Al}}^{\mathrm{mix}}=-38 \mathrm{~kJ} / \mathrm{mol}, \Delta H_{\mathrm{Ce}-\mathrm{Al}}^{\mathrm{mix}}=-38 \mathrm{~kJ} / \mathrm{mol}, \Delta H_{\mathrm{La}-\mathrm{Co}}^{\operatorname{mix}}=$ $-17 \mathrm{~kJ} / \mathrm{mol}, \Delta H_{\mathrm{Ce}-\mathrm{Co}}^{\mathrm{mix}}=-18 \mathrm{~kJ} / \mathrm{mol}, \Delta H_{\mathrm{Co}-\mathrm{Al}}^{\mathrm{mix}}=-19 \mathrm{~kJ} /$ mol. ${ }^{19)}$ The largest negative chemical mixing enthalpy between $\mathrm{La}(\mathrm{Ce})$ and $\mathrm{Al}$ atoms further stabilize the solutesolvent bonding in the first coordination shell thermodynamically, and other negative chemical mixing enthalpies also stabilize the topologically dense packing structure.

The predicted composition of metallic glasses in both systems is $\mathrm{La}(\mathrm{Ce})_{76} \mathrm{Al}_{12} \mathrm{Co}_{12}$, which is denoted by tilted cross in Fig. 1 and Fig. 2, according to the efficient cluster packing model. It is shown in Fig. 1 and Fig. 2 that BMGs in both systems form within the region near the predicted composition with $S_{\text {config }} / R$ ranging from about 0.8 to about 1 . The predicted results based on this simple method combing with the efficient cluster packing model of metallic glasses, chemical mixing enthalpy, and the normalized configurational entropy are in good agreement with experiments, ${ }^{20)}$ when the overlapping among clusters and defects in the efficient cluster packing model are taken into account. ${ }^{16)}$ It also can be seen that two topologically equivalent alloy systems with similar mixing enthalpies between constituents have similar BMG-forming region, as what was expected.

The $\mathrm{Zr}$-Ti-Cu-Ni quaternary alloy system is a pseudoternary $\mathrm{Zr}-\mathrm{Ti}-\mathrm{Cu}(\mathrm{Ni})$ alloy system, due to the equivalent atomic radius between $\mathrm{Cu}$ and $\mathrm{Ni}\left(\mathrm{r}_{\mathrm{Cu}}=0.1278 \mathrm{~nm} \approx\right.$ $\mathrm{r}_{\mathrm{Ni}}=0.12459 \mathrm{~nm}$ ), and the chemical mixing enthalpies between elements are $\Delta H_{\mathrm{Zr}-\mathrm{Ti}}^{\operatorname{mix}}=0 \mathrm{~kJ} / \mathrm{mol}, \Delta H_{\mathrm{Zr}-\mathrm{Ni}}^{\operatorname{mix}}=-49$ $\mathrm{kJ} / \mathrm{mol}, \Delta H_{\mathrm{Zr}-\mathrm{Cu}}^{\operatorname{mix}}=-23 \mathrm{~kJ} / \mathrm{mol}, \Delta H_{\mathrm{Ti}-\mathrm{Ni}}^{\operatorname{mix}}=-35 \mathrm{~kJ} / \mathrm{mol}$, $\Delta H_{\mathrm{Ti}-\mathrm{Cu}}^{\operatorname{mix}}=-9 \mathrm{~kJ} / \mathrm{mol}, \Delta H_{\mathrm{Ni}-\mathrm{Cu}}^{\mathrm{mix}}=4 \mathrm{~kJ} / \mathrm{mol} .{ }^{19)}$ The possible cluster packing are: $\mathrm{Cu}(\mathrm{Ni})$ occupying $\Omega$ sites, $\mathrm{Zr}$ occupying

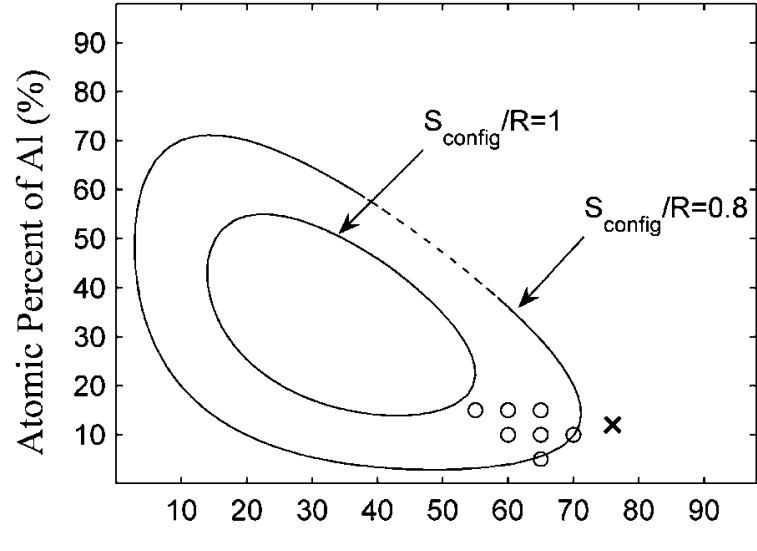

Atomic Percent of Ce (\%)

Fig. 2 The contours of $S_{\text {config }} / R$ being equals to 0.8 and 1 , in the composition diagram of the Ce-Al-Co alloy system. $\mathrm{BMGs}^{20)}$ are denoted by circles, the predicted glass-forming composition is denoted by tilted cross.

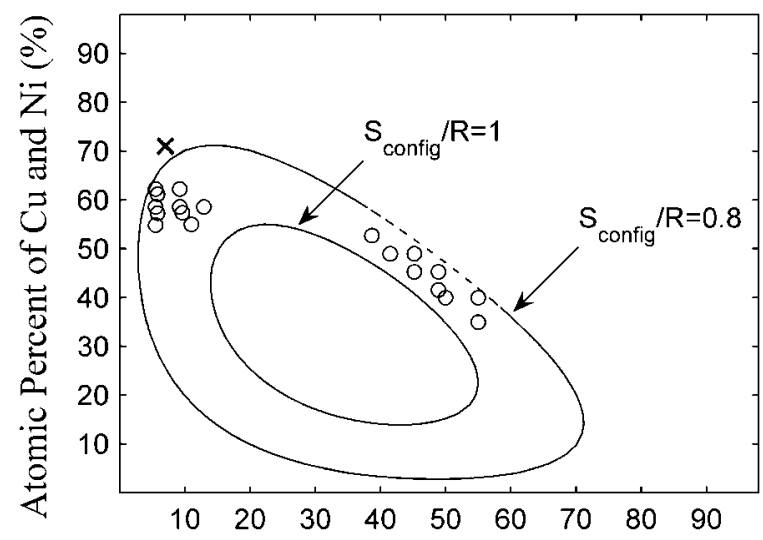

Atomic Percent of $\mathrm{Zr}(\%)$

Fig. 3 The contours of $S_{\text {config }} / R$ being equals to 0.8 and 1 , in the composition diagram of the $\mathrm{Zr}-\mathrm{Ti}-\mathrm{Cu}-\mathrm{Ni}$ quaternary alloy system. $\mathrm{BMGs}^{21)}$ are denoted by circles, the predicted glass-forming composition is denoted by tilted cross.

$\alpha$ sites, $\mathrm{Zr}$ and/or Ti occupying $\beta$ and $\gamma$ sites; $\mathrm{Zr}$ occupying $\Omega$ sites, Ti occupying $\alpha$ sites, Ti and/or $\mathrm{Cu}(\mathrm{Ni})$ occupying $\beta$ and $\gamma$ sites; Ti occupying $\Omega$ sites, $\mathrm{Zr}$ occupying $\alpha$ sites, $\mathrm{Zr}$ and/or $\mathrm{Cu}(\mathrm{Ni})$ occupying $\beta$ and $\gamma$ sites. However, the second and the third packing are not supported because the chemical mixing enthalpy, which represents the degree of bonding, between the solute and solvent atoms $\mathrm{Ti}$ and $\mathrm{Zr}$ is $0 \mathrm{~kJ} / \mathrm{mol}$ in the first coordination shell. As pointed out by Miracle, ${ }^{16)}$ strong solute-solvent bonding is required to form solute-centered cluster in the efficient cluster packing model.

The predicted composition is $\mathrm{Cu}(\mathrm{Ni})_{71} \mathrm{Zr}_{7} \mathrm{Ti}_{22}$, which is denoted by tilted cross in Fig. 3. The composition region near to the predicted composition with $S_{\text {config }} / R$ ranging from about 0.8 to about 1 should be the BMG-forming region. This prediction is confirmed by the good agreement between the predicted and experimental results, ${ }^{21)}$ when the overlapping among clusters and defects in the efficient cluster packing model are taken into account. ${ }^{16)}$ It also can be clearly seen 


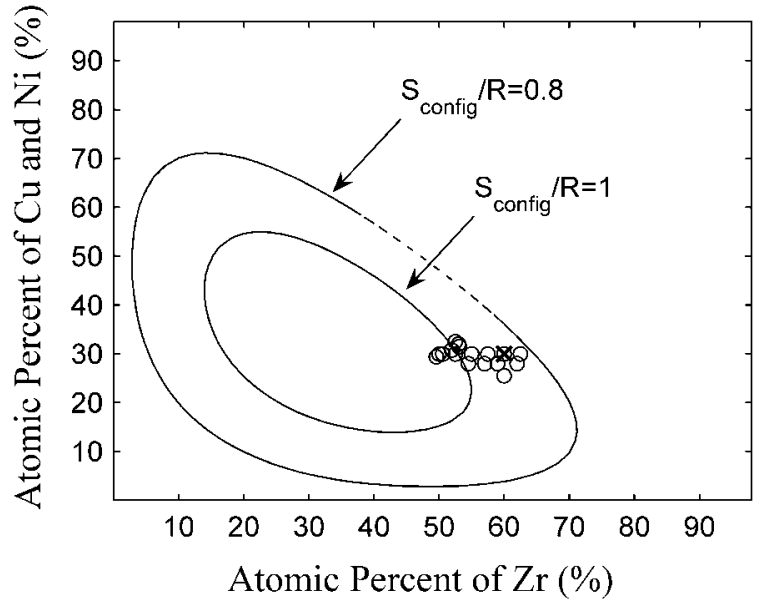

Fig. 4 The contours of $S_{\text {config }} / R$ being equals to 0.8 and 1 , in the composition diagram of the $\mathrm{Zr}$ - $\mathrm{Ti}-\mathrm{Al}-\mathrm{Cu}-\mathrm{Ni}$ quinary alloy system. $\mathrm{BMGs}^{22)}$ are denoted by circles, the predicted glass-forming composition is denoted by tilted cross.

that there are two separate BMG-forming regions in $\mathrm{Cu}-\mathrm{Zr}$ $\mathrm{Ni}$-Ti alloy system, which may result from the Ni-centered clusters with $\mathrm{Zr}$ atoms occupying $\Omega$ sites and Ti-centered clusters with $\mathrm{Ni}$ atoms occupying $\Omega$ sites due to the large negative chemical mixing enthalpies between them.

Similarly, the Zr-Ti-Al-Cu-Ni quinary alloy system is also a pseudo-ternary $\mathrm{Zr}-\mathrm{Ti}(\mathrm{Al})-\mathrm{Cu}(\mathrm{Ni})$ alloy system, due to the equivalent atomic radius between $\mathrm{Cu}$ and $\mathrm{Ni}, \mathrm{Ti}$ and $\mathrm{Al}$. The chemical mixing enthalpies between constituents are: $\Delta H_{\mathrm{Zr}-\mathrm{Ti}}^{\operatorname{mix}}=0 \mathrm{~kJ} / \mathrm{mol}, \quad \Delta H_{\mathrm{Zr}-\mathrm{Ni}}^{\operatorname{mix}}=-49 \mathrm{~kJ} / \mathrm{mol}, \quad \Delta H_{\mathrm{Zr}-\mathrm{Cu}}^{\operatorname{mix}}=$ $-23 \mathrm{~kJ} / \mathrm{mol}, \quad \Delta H_{\mathrm{Zr}-\mathrm{Al}}^{\operatorname{mix}}=-44 \mathrm{~kJ} / \mathrm{mol}, \quad \Delta H_{\mathrm{Ti}-\mathrm{Ni}}^{\mathrm{mix}}=-35 \mathrm{~kJ} /$ $\mathrm{mol}, \Delta H_{\mathrm{Ti}-\mathrm{Cu}}^{\mathrm{mix}}=-9 \mathrm{~kJ} / \mathrm{mol}, \quad \Delta H_{\mathrm{Ti}-\mathrm{Al}}^{\operatorname{mix}}=-30 \mathrm{~kJ} / \mathrm{mol}$, $\Delta H_{\mathrm{Ni}-\mathrm{Cu}}^{\operatorname{mix}}=4 \mathrm{~kJ} / \mathrm{mol}, \quad \Delta H_{\mathrm{Ni}-\mathrm{Al}}^{\mathrm{mix}}=-22 \mathrm{~kJ} / \mathrm{mol}, \Delta H_{\mathrm{Cu}-\mathrm{Al}}^{\mathrm{mix}}=$ $-1 \mathrm{~kJ} / \mathrm{mol} .{ }^{19)}$ With the addition of $\mathrm{Al}$ atoms, the situation is quite different. The large negative mixing enthalpy between $\mathrm{Zr}$ and $\mathrm{Al}$ produces strong chemical short order in the first coordination shell, and the mostly large negative chemical mixing enthalpies further stabilize the efficient fcc packing of clusters with $\mathrm{Zr}$ occupying $\Omega$ sites, $\mathrm{Al}$ occupying $\alpha$ sites, $\mathrm{Cu}(\mathrm{Ni})$ and $\mathrm{Ti}$ occupying $\beta$ sites and/or $\gamma$ sites. Therefore, BMGs form in a narrow composition region, which near to the predicted composition $\mathrm{Zr}_{60} \mathrm{Al}(\mathrm{Ti})_{10^{-}}$ $\mathrm{Cu}(\mathrm{Ni})_{30}$ with $S_{\text {config }} / R$ ranging from about 0.8 to about 1 . It can be seen in Fig. 4 that BMGs prepared in experiments ${ }^{22)}$ are well within the predicted region, when the overlapping among clusters and defects in the efficient cluster packing model are taken into account. ${ }^{16)}$

It can be seen in these figures that in topologically and thermodynamically similar alloy system, BMGs form in similar regions. However, the BMG-forming region is quite different in topologically equivalent but thermodynamically different alloy systems. A strong solute-solvent bonding is required to form a stable cluster in the first coordination shell, when the cluster is efficiently packed.

It could be concluded that a simple method combing topological, chemical analysis and $S_{\text {config }} / R$ can be used to rapidly locate $\mathrm{BMG}$-forming composition region, especially for multicomponent alloy systems, in which the eutectic composition is difficult to obtain.

\section{Summary}

We have evaluated the predictive ability of a simple method combing with topological, chemical analysis and $S_{\text {config }} / R$ in rapidly locating the BMG-forming composition region, in La-Al-Co, Ce-Al-Co ternary alloy systems, Zr-Ti$\mathrm{Cu}-\mathrm{Ni}$ quaternary alloy system and $\mathrm{Zr}-\mathrm{Ti}-\mathrm{Al}-\mathrm{Cu}-\mathrm{Ni}$ quinary alloy system. It was found that the chemical mixing enthalpies between constituents and efficient cluster packing are two dominate factors in BMG formation, and BMGs form in composition region with $S_{\text {config }} / R$ ranging from about 0.8 to about 1 . In topologically and thermodynamically similar alloy system, BMGs form in similar regions. However, the BMG-forming region is quite different in topologically equivalent but thermodynamically different alloy systems. A strong solute-solvent bonding is required to form a stable cluster in the first coordination shell, when the cluster is efficiently packed. It could be concluded that this simple method can be used to rapidly locate BMG-forming composition region, especially for multicomponent alloy systems, in which the eutectic composition is difficult to obtain.

\section{REFERENCES}

1) X. Hu, S. C. Ng, Y. P. Feng and Y. Li: Acta Mater. 51 (2003) 561-572.

2) H. Tan, Y. Zhang, D. Ma, Y. P. Feng and Y. Li: Acta Mater. 51 (2003) 4551-4561.

3) B. C. Giessen: Proc. 4th Int. Conf. on Rapidly Quenched Metals, ed. by T. Masumoto and K. Suzuki, (The Japan Inst. Metals, 1982) pp. 213219.

4) T. Egami and Y. Waseda: J. Non-Cryst. Solids 64 (1984) 113-134.

5) A. L. Greer: Nature 366 (1993) 303-304.

6) M. Fukuhara, M. Takahashi, Y. Kawzoe and A. Inoue: Appl. Phys. Lett. 90 (2007) 073114.

7) D. Turnbull: Contemp. Phys. 10 (1969) 473-488.

8) A. Inoue, T. Zhang and T. Masumoto: J. Non-Cryst. Solids 156-158 (1993) 473-480.

9) Z. P. Lu and C. T. Liu: Acta Mater. 50 (2002) 3501-3512.

10) S. Rao, J. Bhatt and B. S. Murty: Mater. Sci. Eng. A 449-451 (2007) 211-214.

11) H. Cai, H. Chen, W. K. An, J. Y. Tan, Y. Zhou, Y. Pan and G. X. Sun: J. Non-Cryst. Solids 354 (2008) 1808-1816.

12) J. Bhatt, J. Wu, J. Xia, Q. Wang, C. Dong and B. S. Murty: Intermetallics 15 (2007) 716-721.

13) G. Shao, B. Lu, Y. Q. Liu and P. Tsakiropoulos: Intermetallics 13 (2005) 409-414.

14) X. Y. Yan, Y. A. Chang, Y. Yang, F. Y. Xie, S. L. Chen, F. Zhang, S. Daniel and M. H. He: Intermetallics 9 (2001) 535-538.

15) D. Kim, B. J. Lee and N. J. Kim: Scr. Mater. 52 (2005) 969-972.

16) D. B. Miracle: Acta Mater. 54 (2006) 4317-4336.

17) D. B. Miracle: Nature Mater. 3 (2004) 697-702.

18) D. B. Miracle, W. S. Sanders and O. N. Senkov: Phil. Mag. 83 (2003) 2409-2428.

19) A. Takeuchi and A. Inoue: Mater. Trans. 46 (2005) 2817-2829.

20) R. Li, S. Pan, C. Ma and T. Zhang: Acta Mater. 55 (2007) 3719-3726.

21) X. H. Lin and W. L. Johnson: J. Appl. Phys. 78 (1995) 6514-6519.

22) H. Cao, D. Ma, K. C. Hsieh, L. Ding, W. G. Stratton, P. M. Voyles, Y. Pan, M. Cai, J. T. Dickinson and Y. A. Chang: Acta Mater. 54 (2006) 2975-2982. 